\title{
Depth-Resolved Distribution of Particle-Attached and Free-Living Bacterial Communities in the Water Column of the New Britain Trench
}

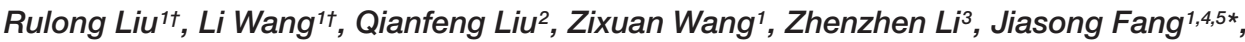 \\ Li Zhang ${ }^{3}$ and Min Luo ${ }^{1}$
}

' Shanghai Engineering Research Center of Hadal Science and Technology, College of Marine Sciences, Shanghai Ocean University, Shanghai, China, ${ }^{2}$ State Key Laboratory of Marine Geology, Tongji University, Shanghai, China, ${ }^{3}$ State Key Laboratory of Geological Process and Mineral Resources, Department of Earth Sciences, China University of Geosciences, Wuhan, China, ${ }^{4}$ Laboratory for Marine Biology and Biotechnology, Qingdao National Laboratory for Marine Science and Technology, Qingdao, China, ${ }^{5}$ Department of Natural Sciences, Hawaii Pacific University, Honolulu, HI, United States

\section{OPEN ACCESS}

Edited by:

Karla B. Heidelberg,

University of Southern California,

United States

Reviewed by:

J. Michael Beman,

University of California, Merced,

United States

Holly M. Simon,

Oregon Health \& Science University,

United States

*Correspondence:

Jiasong Fang

jsfang@shou.edu.cn

†These authors have contributed equally to this work and are the co-first authors.

Specialty section: This article was submitted to

Aquatic Microbiology,

a section of the journal

Frontiers in Microbiology

Received: 18 January 2018 Accepted: 19 March 2018

Published: 04 April 2018

Citation:

Liu R, Wang L, Liu Q, Wang Z, Li Z, Fang J, Zhang L and Luo M (2018)

Depth-Resolved Distribution of Particle-Attached and Free-Living Bacterial Communities in the Water

Column of the New Britain Trench.

Front. Microbiol. 9:625.

doi: 10.3389/fmicb.2018.00625
Particle-attached (PA) and free-living (FL) microorganisms play significant but different roles in mineralization of organic matter $(\mathrm{OM})$ in the ocean. Currently, little is known about PA and FL microbial communities in bathyal and abyssal pelagic waters, and understanding of their diversity and distribution in the water column and their interactions with environmental factors in the trench area is limited. We investigated for the first time the variations of abundance and diversities of the PA and FL bacterial communities in the epi-, bathy-, and abyssopelagic zones of the New Britain Trench (NBT). The PA communities showed decreasing species richness but increasing relative abundance with depth, suggesting the increasing ecological significance of the PA bacteria in the deep ocean. The abundance and diversity of PA and FL bacterial communities in the NBT water column appeared to be shaped by different sets of environment factors, which might be related to different micro-niches of the two communities. Analysis on species distribution suggested that the differences between PA and FL bacteria communities mainly resulted from the different relative abundance of the "shared taxa" in the two types of communities. These findings provide valuable information for understanding the relative ecological roles of the PA and FL bacterial communities and their interactions with environmental factors in different pelagic zones along the vertical profile of the NBT water column.

Keywords: particle-attached, free-living, bacteria, New Britain Trench, vertical variation, abundance, diversity

\section{INTRODUCTION}

The pelagic deep ocean contains $70 \%$ of the ocean's microbial cells and $60 \%$ of its heterotrophic activity, playing a significant role in regulating the biogeochemical cycles of the earth (Arístegui et al., 2009). About $1-40 \%$ of the photosynthetically produced organic matter (OM) is exported vertically in the form of sinking particulates (POM), serving as major source of organic matter in the deep ocean (Ducklow et al., 2001; Herndl and Reinthaler, 2013). During sinking, particles are effectively colonized by particle-attached (PA) microorganisms that convert the high-molecular weight organic matter into small substrates available for cellular metabolism (Arnosti, 2011). 
A fraction of the POM is decomposed and released as dissolved organic matter (DOM) into the surrounding seawater, forming a DOM plume which is further utilized by free-living (FL) microbes (Azam and Malfatti, 2007; Arnosti, 2011; Jiao et al., 2014; Fang et al., 2015). Thus, the fate of OM in the deep ocean is largely determined by the abundance, diversity and activities of the PA and FL microbial communities along the depth profile of the water column (Herndl and Reinthaler, 2013; Jiao et al., 2014; Fang et al., 2015).

The physical and chemical conditions in the water column of the ocean are not uniform, and great variations exist for environmental factors with increasing depth (Jamieson et al., 2010). These factors provide strong selection stresses on microbial communities along the vertical water column. As a result, clear depth stratification of microbial communities has been widely reported in the open ocean (DeLong et al., 2006; Brown et al., 2009; Agogué et al., 2011; Nunoura et al., 2015, 2016; Walsh et al., 2016). However, the majority of the existing studies mainly targeted the whole microbial community. As the PA and FL assemblages play ecologically distinct roles in mediating biogeochemical cycles in the ocean (Azam and Malfatti, 2007; Arnosti, 2011; Jiao et al., 2014; Fang et al., 2015), understanding compositional differences between the two communities as well as their relative responses to the changes of environmental factors is important. Currently, the PA and FL communities have been reported to harbor different groups of microbial lineages in various marine environments including coastal or surface water (Mohit et al., 2014; Zhang et al., 2016), bathypelagic water (Wilkins et al., 2013; Salazar et al., 2016; Milici et al., 2017) or even extreme depths of hadalpelagic habitats $(>6000 \mathrm{~m}$ ) (Eloe et al., 2011b; Tarn et al., 2016). However, these studies mainly focus on the shallower waters or a particular depth in the deep ocean, and understanding on variations of PA and FL communities along the vertical profile is limited (Li et al., 2015; Milici et al., 2017). Existing studies generally revealed different patterns of vertical variations between the PA and FL bacterial communities in the water column above the bathypelagic depth ( $\mathrm{Li}$ et al., 2015; Milici et al., 2017). It is not known how the abundance and diversity of PA assemblages change relative to those of their FL counterparts from the surface to the abyssopelagic zone. On the other hand, biogeographical distribution of the PA and FL microbial communities at depths around $4000 \mathrm{~m}$ in the global ocean was found to be controlled by different sets of environmental factors (Salazar et al., 2016), suggesting that PA and FL microbes may respond differently to environmental conditions at a horizontal scale in bathypelagic waters. It is not clear whether the two microbial communities respond differently to the changes of environmental conditions along vertical scale from surface to abyssopelagic depths, and if so, what are the major factors controlling the vertical variations of PA and FL communities?

The hadal trenches are the deepest part of the ocean. With unique tectonic, topographic, bathymetric and hydrographic features, trenches have been recently discovered as hotspots of microbial activities in the deep ocean (Glud et al., 2013), probably playing an important role in marine biogeochemical cycles (Jamieson et al., 2010; Ichino et al., 2015; Liu et al., 2017).
However, studies conducted on PA and FL microbial communities in trench areas are still scarce (Eloe et al., 2011b; Tarn et al., 2016), little is known about the relative changes of PA and FL microbial fractions along the vertical gradients of water column of the trenches.

In this study, we investigate for the first time the changes of abundance and diversity of the PA and FL bacterial communities in the water column of the New Britain Trench (NBT). Water samples were collected along the vertical profile from the surface to the abyssopelagic zone. The objectives are to (1) determine the abundance and diversity of PA and FL bacterial communities from the surface to the abyssopelagic zone; (2) reveal the succession of PA and FL bacterial taxa in response to environmental factors in the water column and the implications for biogeochemical cycles in the oceans.

\section{MATERIALS AND METHODS}

\section{Water Sampling and Physical, Geochemical Parameter Measurements}

Water samples were taken in August 2016 at station W $\left(06^{\circ} 59.5477^{\prime} \mathrm{S}, 149^{\circ} 46.6129^{\prime} \mathrm{E}\right)$ in the western New Britain Trench during a cruise aboard M/V Zhang Jian. The full depth of this station is $6700 \mathrm{~m}$, and water samples were collected from 75, 200, 1000, 2000, 3000, 4000, 5000, and $6000 \mathrm{~m}$ using Niskin bottles fitted on a Sea-Bird Carousel equipped with a conductivitytemperature-depth (CTD) sensor (Sea-Bird SBE 911plus). For each depth, around $50 \mathrm{~L}$ of water was taken and was processed immediately onboard the ship: (1) duplicate $20 \mathrm{~L}$ of the water were filtered sequentially through 3 and $0.2 \mu \mathrm{m}$ polycarbonate filters (PC, Millipore) to collect PA and FL microbes, respectively. Duplicated filters were obtained for each size fraction and were immediately stored at $-80^{\circ} \mathrm{C}$; (2) for POC and PON analysis, 7-9 L of the water was filtered through $0.7 \mu \mathrm{m}$ nominal pore size glass fiber filters (GF-75, Whatman) which were pre-combusted in a muffle furnace at $500^{\circ} \mathrm{C}$ for $12 \mathrm{~h}$. The membrane filters were stored at $-20^{\circ} \mathrm{C}$ after filtration. The filtrates were also stored at $-20^{\circ} \mathrm{C}$ for DOC analysis; (4) Triplicated $100 \mathrm{~mL}$ of the water were fixed in paraformaldelhyde (PFA, 1\% final concentration) and stored for later microscopic counting of the microbial cells; (5) The remaining water was stored at $-20^{\circ} \mathrm{C}$ for inorganic nutrient measurements.

Physical characteristics of the water including depth, salinity and temperature were measured with CTD sensors during sampling. Concentrations of POC and PON were determined with a PE2400 Series II CHNS/O analyzer (Perkin Elmer, United States) (Chen et al., 2008). Dissolved organic carbon was measured using a Shimadzu TOC-VCHP analyzer with a TNM-1 Total Nitrogen module (Shimadzu Corp., Japan). Seawater nutrients $\left(\mathrm{NO}_{3}{ }^{-}, \mathrm{NO}_{2}{ }^{-}, \mathrm{NH}_{4}{ }^{+}\right.$, and $\left.\mathrm{PO}_{4}{ }^{3-}\right)$ were determined using a QuAAtro autoanalyzer (Seal Analytical, United Kingdom).

\section{Cell Counting}

In laboratory, PFA fixed cells were filtered onto $0.22 \mu \mathrm{m}$ pore size black polycarbonate filters (diameter, $25 \mathrm{~mm}$; 
Whatman-Nucleopore) and stained with DAPI (4',6diamidino-2-phenylindole). Bacterial cells were counted under epifluorescent microscopy (Nikon microscope, model Eclipse Ni-U). For each sample, no less than 20 microscopic fields were counted and cell abundance was calculated according to Liu et al. (2010).

\section{DNA Extraction and PCR Amplification}

In this study, we applied two different DNA extraction methods and two primer sets targeting different hypervariable regions of 16s rRNA gene. Two sets of data were generated for each of the samples, and were then combined into one data set according to the method described in a later section about sequences analysis.

For each depth, duplicate PC filters were obtained for both 3 and $0.2 \mu \mathrm{m}$ fractions (as described above). The 1st filter was lysed using lysozyme (30 $\mathrm{mg} \mathrm{ml}^{-1}$ ) and then extracted with AllPrep DNA/RNA Mini Kit (Qiagen). The 2nd filter was extracted with FastDNA ${ }^{\text {TM }}$ SPIN Kit for Soil DNA Extraction (MP) according to manufacturer's protocols. The concentration and quality of final DNAs were determined by NanoDrop 2000 UV-vis spectrophotometer (Thermo Scientific, Wilmington, DE, United States). DNA samples from the 1st replicates were amplified with barcoded primers 338F (5'-ACTCCTACGGGAGGCAGCAG-3') and 806R (5'-GGACTACHVGGGTWTCTAAT- $\left.3^{\prime}\right)$ targeting the $\mathrm{V} 3-\mathrm{V} 4$ hypervariable regions. DNAs from the 2nd replicates were amplified with barcoded primers 515F (5'-GTGCCA GCMGCCGCGG-3') and 907R (5'-CCGTCAATTCMTTTRA GTTT- $3^{\prime}$ ) targeting the V4-V5 hypervariable regions of $16 \mathrm{~s}$ rRNA gene. PCR reactions were conducted using a thermocycler PCR system (GeneAmp 9700, ABI, United States) with the following program: $5 \mathrm{~min}$ of denaturation at $95^{\circ} \mathrm{C}, 27$ cycles of $60 \mathrm{~s}$ at $95^{\circ} \mathrm{C}, 60 \mathrm{~s}$ at $55^{\circ} \mathrm{C}$ for annealing, and $60 \mathrm{~s}$ at $72^{\circ} \mathrm{C}$ for extension, and a final extension step at $72^{\circ} \mathrm{C}$ for $10 \mathrm{~min}$. PCR reactions were performed in triplicate $50 \mu \mathrm{L}$ mixture with each containing 1X ExTaq buffer, $0.2 \mathrm{mM}$ of each dNTP, $0.2 \mu \mathrm{M}$ of each primer, $1 \mathrm{U}$ of ExTaq polymerase (TAKARA, China) and $1 \mu$ l DNA. PCR products were purified from $2 \%$ agarose gel using AxyPrep DNA Gel Extraction Kit (Axygen Biosciences, Union City, CA, United States) and quantified using QuantiFluor $^{\mathrm{TM}}$-ST (Promega, United States). DNAs from PA and FL fractions of $3000 \mathrm{~m}$ and PA fraction of $5000 \mathrm{~m}$ were failed in PCR amplification with $338 \mathrm{~F} / 806 \mathrm{R}$, so these samples were excluded from the diversity analysis.

\section{llumina MiSeq Sequencing and Sequences Processing}

Purified amplicons were pooled in equimolar and paired-end sequenced $(2 \times 300)$ on an Illumina MiSeq platform (Illumina, San Diego, CA, United States) according to standard protocols by Majorbio Bio-Pharm Technology Co. Ltd. (Shanghai, China). Raw fastq files were demultiplexed, quality-filtered by Trimmomatic (Bolger et al., 2014) and assembled by FLASH (Magoc and Salzberg, 2011) with the following criteria: (i) Reads with an average quality score $<20$ over a 50 bp sliding window at any site were truncated; (ii) Primers were checked by allowing 2 nucleotides mismatching, and reads containing ambiguous bases were removed; (iii) Sequences with overlaps of more than $10 \mathrm{bp}$ were assembled according to their overlap sequence. Chimeric sequences were identified and removed using UCHIME and operational taxonomic units (OTUs) were clustered with 97\% similarity cutoff using UPARSE (version 7.1 ${ }^{1}$. The taxonomy of each OTU was assigned by RDP Classifier ${ }^{2}$ against the Silva16S rRNA database (SSU123) with a confidence threshold of $70 \%$.

\section{Diversity Analysis and Statistical Tests}

Two datasets, named "Qiagen-338-806" and "MP-515-907" were generated for each of the samples, and were combined into one dataset according to Vahjen et al. (2010). Briefly, the sequences from two datasets were randomly resampled to ensure each sample from the two datasets has the same number of sequences (Ghiglione et al., 2012). This step resulted in two new sets of data with 20,118 sequences for each of the samples. These two datasets were then merged by taking only sequences from the primer set that yielded the higher number of reads for a specific OTU assignment in a sample (Vahjen et al., 2010), which generated a new dataset with 35,877 to 40,046 sequences for the 13 samples tested. The newly generated datasets showed much improved resolution of microbial diversity (see Results).

The diversity indices including species richness (at OTUs level), Pielou's evenness, Shannon index, Simpson index were calculated with PRIMER 6.0 package using OTU table of the merged data set generated as described above. Venn diagram was produced with VENNY 2.1 (Oliveros, 2007-2015) to show the changes of OTU distribution in PA and FL fractions at different depth. Lists of OTUs that were exclusively present in either PA or FL fractions and those present in both fractions were exported from Venn analysis, and the relative abundance of those listed OTUs in the total sequences of a particular sample were manually examined in the OTU table. A Bray-Curtis similarity matrix was constructed based on species composition at OTU level to show the $\beta$-diversity between different samples and was visualized using non-metric multidimensional scaling (nMDS) and hierarchical clustering (UPGMA) using the PRIMER 6.0 package. One way Analysis of Similarity (ANOSIM) was performed to test for differences between different groups. Samples that were clustered together in nMDS were regarded as the same group and used to compare with other groups. Similarity percentage (SIMPER) (Clarke and Warwick, 2001) was used to identify major OTUs responsible for dissimilarity between different bacterial groups. Relationships between the species composition of bacterial communities and environmental parameters were assessed using canonical correspondence analysis (CCA) (CANOCO version 4.5) (Ter Braak, 1986). The environmental factors we tested in this study include physical parameters (pressure, temperature, and salinity), inorganic nutrients (nitrate, nitrite, ammonia, phosphate) and organic contents (POC, PON, and DOC). All of the environmental factors were included in the stepwise "forward

\footnotetext{
${ }^{1}$ http://drive5.com/uparse/

${ }^{2}$ http://rdp.cme.msu.edu/
} 
selection" with Monte Carlo permutation test (999 permutations) to produce an optimal CCA model, and environmental factors with significant conditional effects in either PA or FL bacterial community were selected.

\section{Quantitative PCR Determining the Copy Numbers of Bacterial 16s rRNA Gene}

Each DNA sample was tested with SYBR Green ${ }^{\circledR}$ qPCR assay Eub338F/Eub518R (Thijs et al., 2017) to determine the copy number of PA and FL bacterial 16s rRNA gene. All qPCR assays were performed in $20-\mu \mathrm{l}$ reactions, each contained $2 \mu \mathrm{l}$ of DNA and $500 \mathrm{nM}$ of each primer in 2X AceQ SYBR Green ${ }^{\circledR}$ qPCR Master Mix (Vazyme). Duplicate reactions were used for each sample. The thermal cycles on the ABI 7500 (Applied Biosystems) were the following: initial denaturation $\left(95^{\circ} \mathrm{C}\right)$ for $5 \mathrm{~min}$, followed by 40 cycles of denaturation $\left(95^{\circ} \mathrm{C}\right)$ for $5 \mathrm{~s}$, annealing at $55^{\circ} \mathrm{C}$ for $30 \mathrm{~s}$ and extension at $72^{\circ} \mathrm{C}$ for $40 \mathrm{~s}$. A melting curve analysis was included in each run of $\mathrm{qPCR}$ to check the specificity of amplification. Cycle of threshold (Ct) was calculated using the ABI 7500 software with the auto-baseline and auto-threshold functions. Standard curves of Ct vs. gene copy numbers were constructed using serial dilutions of linearized plasmids containing amplicon fragment of Eub338F/Eub518R.

\section{RESULTS}

\section{Physical-Chemical Parameters and Microbial Cell Abundance}

Temperature continuously decreased from $28.4^{\circ} \mathrm{C}$ at surface water to around $2.2^{\circ} \mathrm{C}$ at $2000 \mathrm{~m}$ and maintained at around $1.9-2.3^{\circ} \mathrm{C}$ from 2000 to $6000 \mathrm{~m}$. Salinity showed gradual increase from $34.4 \mathrm{PSU}$ at surface to $35.7 \mathrm{PSU}$ at $180 \mathrm{~m}$, decreased to $34.5 \mathrm{PSU}$ at $1000 \mathrm{~m}$, and then maintained at around 34.5-34.7 PSU until $6000 \mathrm{~m}$ (Figure 1A). Nitrate and phosphate concentrations were the lowest at surface water and the highest at around $1000 \mathrm{~m}$, while the concentration of nitrite fluctuated along the whole water column with a decreasing trend (Figure 1B). POC and PON concentrations were continuously decreasing with increasing depth. DOC showed similar trend, but its concentration remained relatively constant below $1000 \mathrm{~m}$ (Figure 1C). Microbial cell abundance ranged from $3.14 \pm 1.61 \times 10^{5}$ cells $/ \mathrm{ml}$ in surface water to $7.17 \pm 9.23 \times 10^{3}$ cells $/ \mathrm{ml}$ at $2000 \mathrm{~m}$ and remained relatively constant from 2000 to $6000 \mathrm{~m}$ with an average value of $9.75 \times 10^{3}$ cells $/ \mathrm{ml}$ (Figure 1D). It is interesting to note that the relative abundances of PA and FL bacteria, as determined by qPCR quantification of bacterial $16 \mathrm{~s}$ rRNA genes, showed reversed vertical trends. The relative abundance of PA bacteria increased and that of FL bacteria decreased with depth (Figure 1D).

\section{Vertical Variations in Diversity of the PA and FL Bacterial Communities}

It has been widely reported that different DNA extraction methods and primer sets targeting different hypervariable regions of $16 \mathrm{~s}$ rRNA gene would reveal distinct species compositions of natural microbial communities (Vahjen et al., 2010; Cai et al., 2013; Starke et al., 2014; Wang et al., 2015). In some extreme cases, dominant taxa revealed from one combination of DNA extraction and primer set can become rare taxa or even disappear in another combination (Cai et al., 2013; Starke et al., 2014). Therefore, combining data from different primer sets has been suggested to maximize the detection of microbial diversity (Vahjen et al., 2010; Wang et al., 2015). In this study, we applied two different DNA extraction methods and two primer sets targeting different hypervariable regions of 16s rRNA gene. Two sets of data were generated for each of the samples, and were then combined into one dataset. Similar to previous findings (Vahjen et al., 2010; Cai et al., 2013; Starke et al., 2014; Wang et al., 2015), the species composition of the microbial communities showed great variations between the two original datasets (Supplementary Figures S1, S2). In addition, the original datasets "Qiagen-338-806" and "MP-515-907" revealed 2,438 and 1,947 OTUs, respectively. The combined dataset had 3,313 OTUs (Supplementary Table S1), suggesting greatly improved resolution of microbial diversity.

Species richness of the PA and FL bacterial communities showed distinct vertical trends: richness for the PA assemblages were the highest at $200 \mathrm{~m}$ and showed a general trend of decreasing with depth; whereas richness for the FL assemblage increased with depth, with the highest value at $6000 \mathrm{~m}$ (Figure 1E). Different from species richness, changes of Pielou's evenness and Shannon and Simpson indexes showed similar patterns of vertical variation for both PA and FL bacterial communities, with lowest value at $1000 \mathrm{~m}$ and highest values at 200 and $6000 \mathrm{~m}$ (Supplementary Figure S3).

Proteobacteria was the single dominant phylum in the entire water column of the NBT, accounting for $41.8-82.7 \%$ of the total sequences retrieved from different depths, with relatively higher proportions at $1,000-4,000 \mathrm{~m}$ depth and lower proportions at surface and abyssal depth (Figure 2 and Supplementary Figure S4). Gamma-, Alpha-, Delta-, and Beta-proteobacteria were the dominant classes of Proteobacteria, without clear differences between the two lifestyles (PA vs. FL) (Figure 2 and Supplementary Figure S4). Cyanobacteria were most abundant at $75 \mathrm{~m}$ in both the PA and FL bacterial communities, but their abundance declined sharply with depth, and PA maintained relatively higher abundance than FL communities at all depths (Figure 2). The relative abundance of Bacili class gradually increased with depth and was constantly higher in the PA than the FL communities in the whole water column (Figure 2). The relative abundances of Actinobacteria and Flavobacteria were consistently higher in the PA than in the FL bacterial communities in waters deeper than $200 \mathrm{~m}$ (Figure 2). In contrast, the SAR406 and SAR 202 clades displayed much higher relative abundances in the FL than in the PA communities in deep waters (Figure 2).

Non-metric multidimensional scaling (nMDS) and hierarchical clustering (UPGMA) analyses showed obvious differences in species composition between the communities (Figure 3). Overall, the samples were clustered into three large 


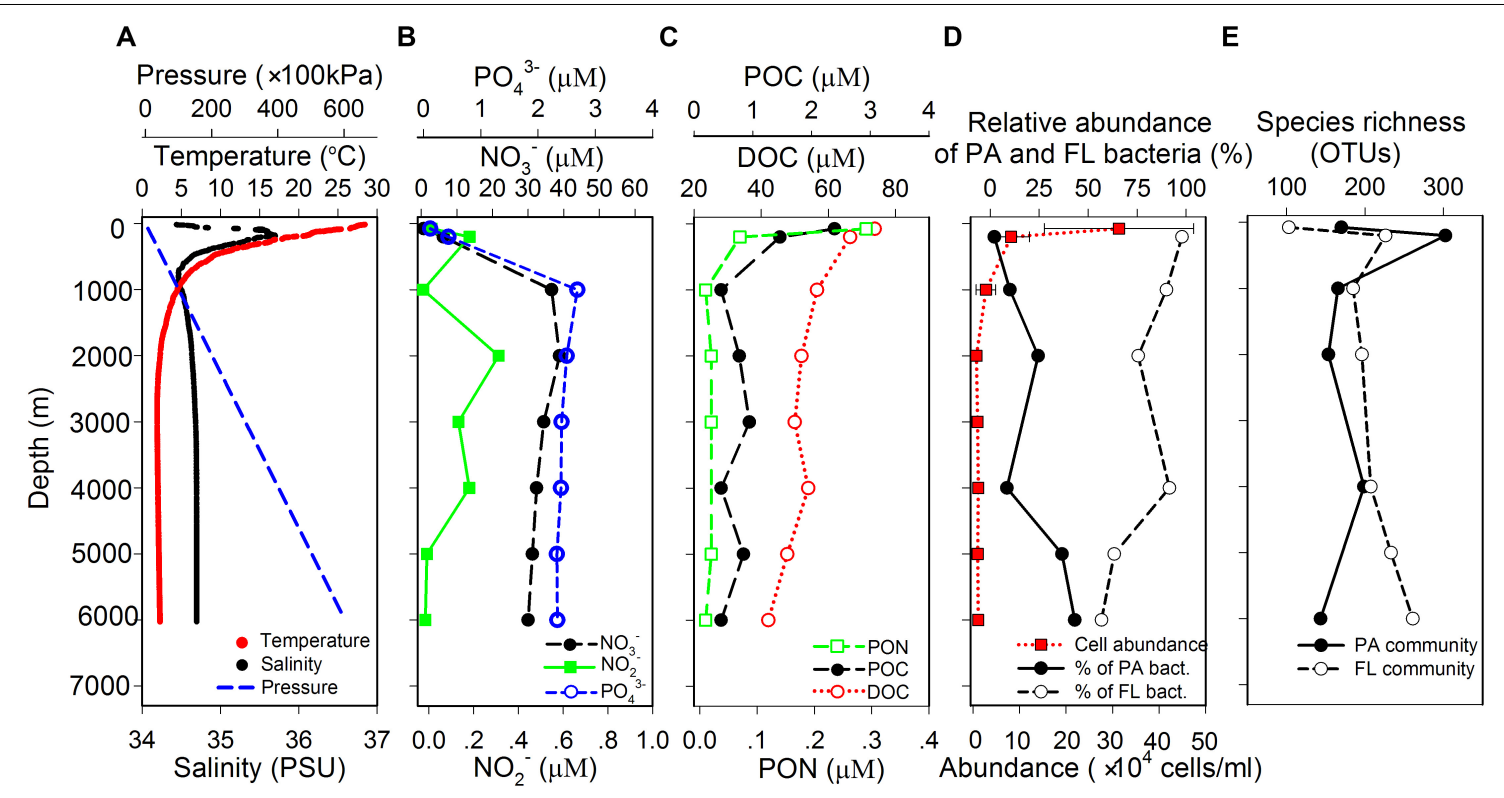

FIGURE 1 | Vertical variations of (A) physical parameters, (B) concentration of inorganic nutrients, (C) concentration of organic matter, (D) cell abundance of total prokaryotes, relative abundance of the PA and FL bacteria, and (E) species richness of the PA and FL bacterial communities in the water column of the New Britain Trench.

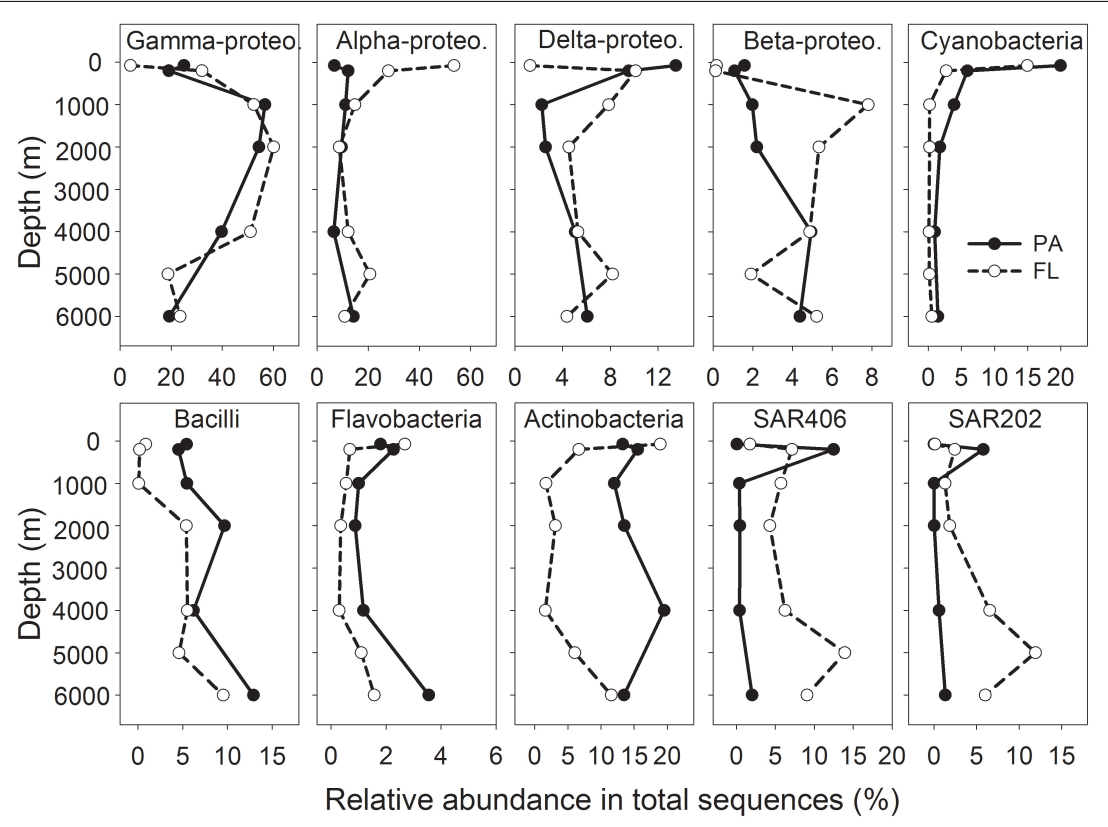

FIGURE 2 | Vertical variations of major bacterial taxa at the class level for PA and FL bacterial communities. Shown are the top 10 classes that have the highest average abundances among all samples.

groups, roughly representing different pelagic zones along the depth profile, i.e., the epipelagic zone (75 and $200 \mathrm{~m}$ ), the bathypelagic zone $(1000,2000$, and $4000 \mathrm{~m}$ ), and the abyssopelagic zone (5000 and $6000 \mathrm{~m}$ ). It was also clear that, within each pelagic zone, the respective PA and FL bacterial communities tend to form different groups (Figure 3). Analysis of similarity (ANOSIM) supported the nMDS groupings: the differences between the pelagic zones were significant (Global $R=0.708, P=0.001$, Table 1), while the differences between the $\mathrm{PA}$ and FL fractions in the whole water column were much lower ( $R=0.187, P=0.065$, Table 1$)$, suggesting that vertical depth stratification is more important than trophic lifestyle in shaping the species composition of bacterial communities in the water column of the NBT. 


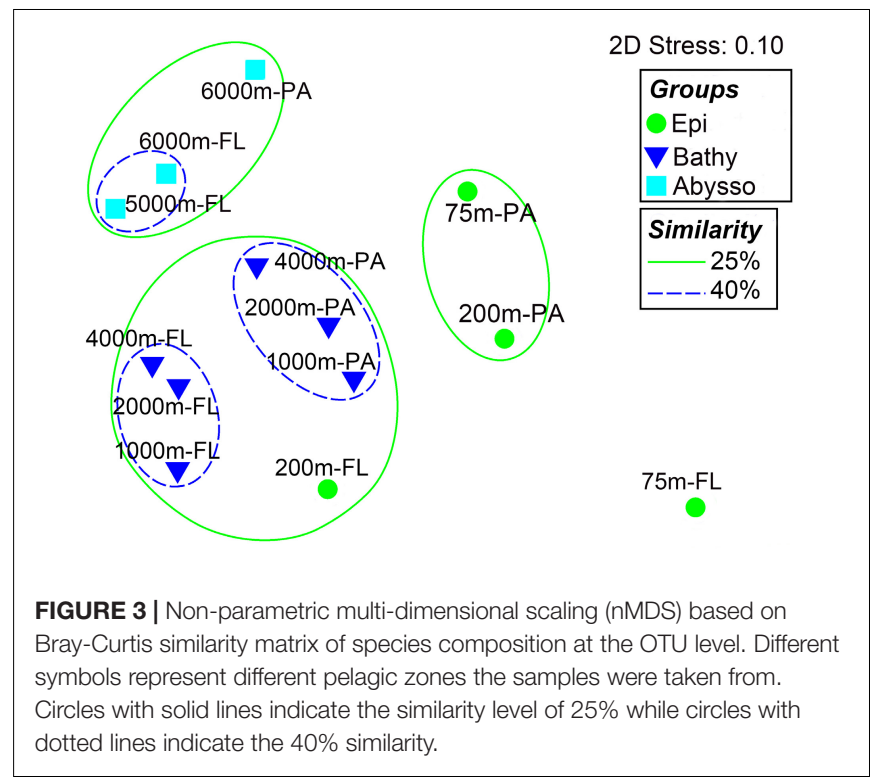

Canonical correspondence analysis was further conducted to show the correlations between the major environmental factors and the observed differences in species composition between the $\mathrm{PA}$ and FL bacterial communities (Figure 4). The results showed that the first two CCA axes explained $55.9 \%$ of the variations for species composition of the PA communities, and $66.1 \%$ of the variations for the FL communities. Monte Carlo test on significance of the first CCA axes showed that only the CCA ax for FL communities was statistically significant $(P=0.016)$ while that for the PA communities was not $(P=0.053)$. Among the tested environmental factors, phosphate was the statistically significant variable associated with the vertical variations of the PA bacterial communities $(P=0.031)$, while pressure $(P=0.008)$ and PON concentration $(P=0.009)$ were the statistically significant variables associated with the vertical pattern of FL bacterial communities.

\section{Distribution of Different Bacterial Lineages in PA and FL Fractions}

Venn analysis showed that the proportion of the shared OTUs between the PA and FL bacterial communities ranged between

TABLE 1 | Analysis of similarity (ANOSIM) between trophic lifestyles (PA vs. FL) (Comparison 1) and between the pelagic zones (Comparison 2).

\begin{tabular}{llc}
\hline ANOSIM & $\boldsymbol{R}$ & $\boldsymbol{P}$ \\
\hline $\begin{array}{l}\text { Comparison 1 } \\
\text { PA vs. FL }\end{array}$ & 0.187 & 0.065 \\
Comparison 2 & & \\
Epi vs. Bathy & 0.667 & 0.005 \\
Epi vs. Abysso & 0.741 & 0.029 \\
Bathy vs. Abysso & 0.840 & 0.012 \\
Global & 0.708 & 0.001 \\
\hline The R-value shows differences between the two groups compared, while the &
\end{tabular}

$22.8 \%$ (at $1000 \mathrm{~m}$ ) to $52.9 \%$ (at $200 \mathrm{~m}$ ), with an average of $32.3 \%$; while the proportion of OTUs present exclusively in the PA communities ranged between $17.4 \%$ at $6000 \mathrm{~m}$ and $49.1 \%$ at $75 \mathrm{~m}$ (average value of $33.3 \%$ ); and that of OTUs present exclusively in FL communities ranged between $15.9 \%$ at $75 \mathrm{~m}$ and $54.6 \%$ at $6000 \mathrm{~m}$, with an average of $34.9 \%$ (Figure 5). However, when taking into consideration of the relative abundance of each OTU in total sequence reads of different samples, we found that OTUs commonly present in both the PA and FL communities accounted for $61.0-95.3 \%$ of the total reads of the samples, with an average of $82.2 \%$ (Figure 5 ). In other words, on average $82.2 \%$ of the reads from the tested samples belonged to OTUs that present in both the PA and FL bacterial communities.

SIMPER analysis was applied to identify the "indicative OTUs" that were responsible for the observed dissimilarities between the PA and FL communities in the NBT water column. In this study, "indicative OTUs" were defined as OTUs that contributed more than $1 \%$ dissimilarities between the two bacterial communities (Figure 6). As a result, 17, 13, and 14 indicative OTUs were identified from the epipelagic, bathypelagic and abyssopelagic zones, respectively. The OTUs had uneven distributions in the PA and FL bacterial communities, but most of them presented in both types of the bacterial communities. For instance, among the identified indicative OTUs, 16 from the epipelagic zone, 11 from the bathypelagic zone, and 9 from the abyssopelagic zone were present in both the PA and FL bacterial communities; only minor proportions of indicative OTUs were present exclusively in either the PA or FL communities (Figure 6 and Supplementary Tables S2-S4). OTU6043, an unclassified Rhodococcus was abundant in PA communities throughout the whole water column, with much higher relative abundance in PA (5.2-10.2\%) than FL (0.0-3.0\%) communities (Figure 6 and Supplementary Tables S2-S4). OTU2045 from Alteromonas was the dominant taxon in both PA (2.2-34.1\%) and FL (6.3-32.8\%) communities throughout the water column, and their preference of lifestyle varied at different depth (Figure 6 and Supplementary Tables S2-S4). Other indicative OTUs were enriched in either PA or FL communities only in one of the pelagic zones (Figure 6).

\section{DISCUSSION}

\section{Variations in Diversity and Abundance of the PA and FL Bacterial Communities in the NBT Water Column}

In this study, the relative abundance of PA bacteria showed an increasing trend with depth (Figure 1D), indicating the potentially increasing ecological significance of PA bacterial communities in the deep ocean comparing to shallower depths. This result could also partially explain the accumulating findings in the literature that bacterial communities in the deep ocean are typically enriched for taxa and genomic features with a particleor surface-associated lifestyle (DeLong et al., 2006; Lauro et al., 2009; Eloe et al., 2011a; Herndl and Reinthaler, 2013; Giovannoni et al., 2014; Thrash et al., 2014). In contrast to the changes of bacterial abundances, species richness of the PA bacterial 

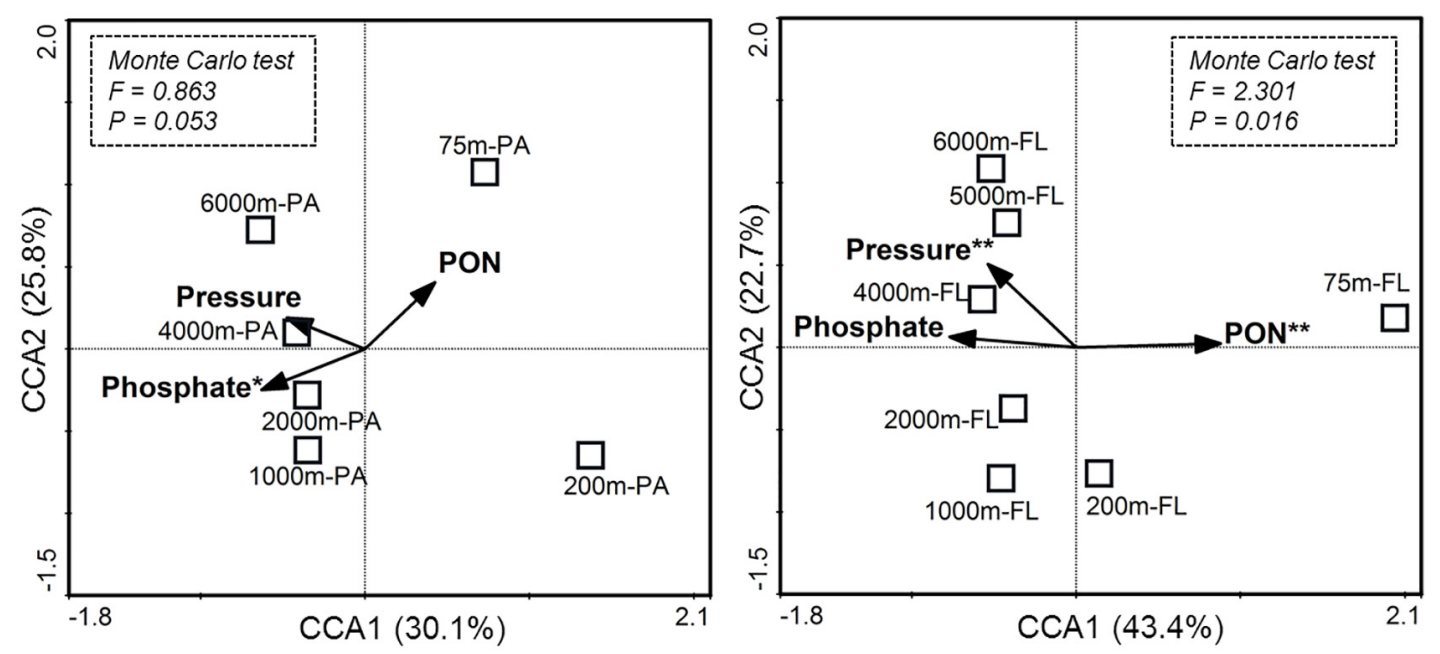

FIGURE 4 | Ordination diagram of the first two axes in canonical correspondence analysis (CCA) for particle-attached (PA) and free-living (FL) bacterial communities from different depths. Each square represents an individual sample. The vectors indicate constrained environmental variables that showed significant effects on species composition of either PA or FL bacterial community, as assessed by the marginal effect of the terms. For each diagram, environmental variables marked with asterisks are statistically significant $\left({ }^{*} P<0.05\right.$; $\left.{ }^{*} P<0.01\right)$. The significance of the first canonical axis was tested via Monte Carlo test with 999 permutations, and the results are shown in the rectangles with dotted lines.

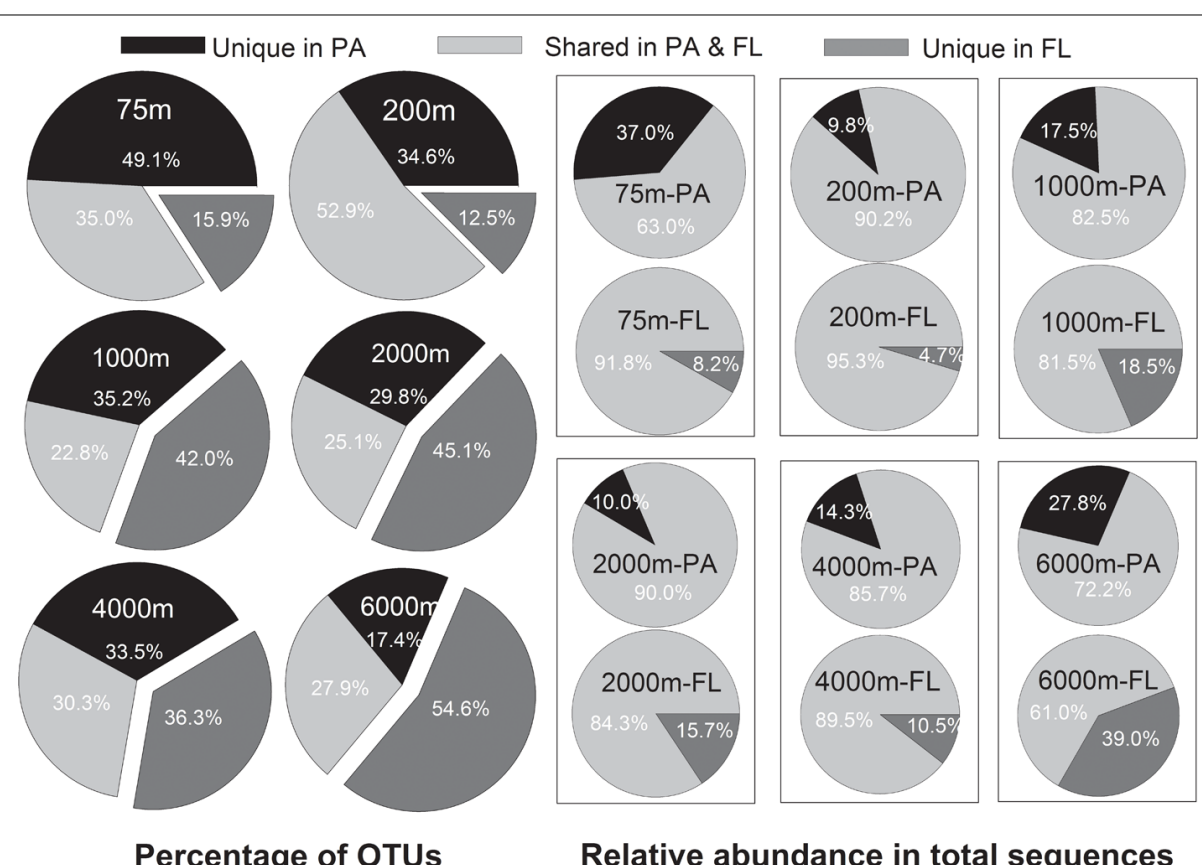

FIGURE 5 | Operational taxonomic units (OTUs) distribution in PA and FL bacterial communities. Larger pie charts at left side show the percentage of shared or unique OTUs in PA and FL bacterial communities at different depths. The smaller pie charts on the right side show the relative abundance of shared or unique OTUs in the total sequences of individual samples at different depths.

community showed a general trend of decreasing while that for the FL community increased with depth (Figure 1E). As a result, species richness was higher in PA than FL bacterial communities in the surface water (epipelagic zone), and higher in FL than PA communities at the bathyal and abyssal depths (Figure 1E). Our results for the epipelagic water are consistent with previous studies conducted at similar depths (Crespo et al., 2013; BižicIonescu et al., 2014; Rieck et al., 2015). For deeper waters, although higher richness in the PA bacterial communities have been reported for samples from the Southern Ocean (Milici et al., 2017) and the Puerto Rico Trench (Eloe et al., 2011b), results from other studies with larger datasets and from wider range of 


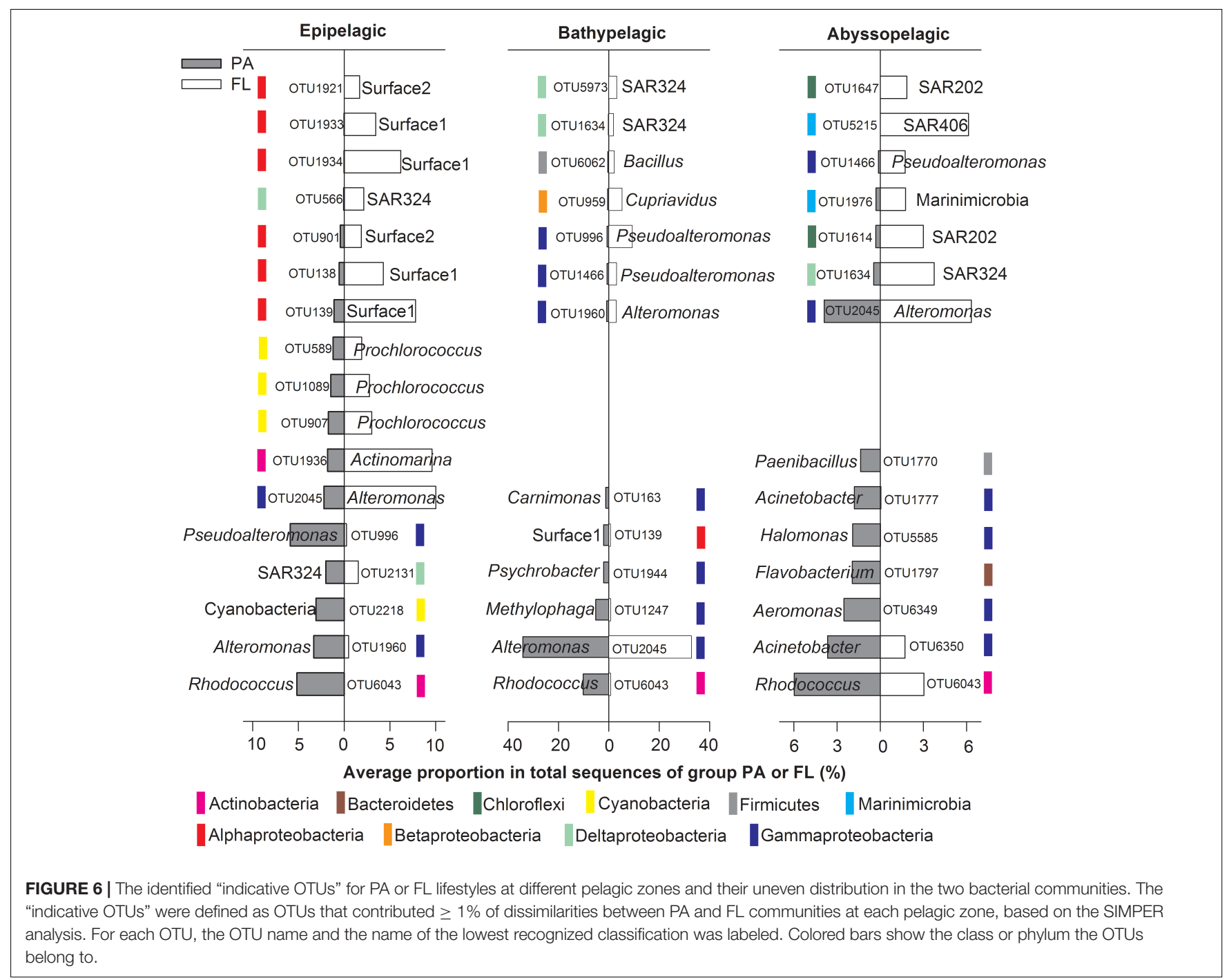

world oceans support our observations, i.e., species richness is higher for FL than PA in the deep ocean (Salazar et al., 2015, global scale bathyal waters; Tarn et al., 2016, multiple sites along the Mariana Trench; Ghiglione et al., 2007, the Mediterranean Sea).

The opposite trends of changes in abundance and species richness may be related to the changes of quantity and bioavailability of organic matter in the particles and the surrounding water along the depth profile and the biogeochemical processes in which the PA and FL communities are involved. The amount and lability of dissolved organic matter decreases with depth in the ocean (Jiao et al., 2010, 2014), leading to the gradual decreasing of heterotrophic bacterial biomass. However, as the descending particles contain higher amount of carbon and nutrients relative to the surrounding water and are preferred hotspots for microbial colonization (Fang et al., 2015; Dang and Lovell, 2016), the rate of decreasing in bacterial biomass on the particles may be less than that in the surrounding waters. As a result, the relative abundance of PA bacteria increased with depth. For species richness, it has been hypothesized that given the constrained space and limited resources on particles, only bacterial taxa that could further hydrolyze the less labile OM could actively colonize on particles in the deeper water. The growth of these taxa may compete with or even inhibit the growth of other attached bacterial taxa (Dang and Lovell, 2016), thus resulting in detachment and reduced species richness of the PA bacteria and increased species numbers of the FL communities in the deep (Kiørboe et al., 2003; Tamburini et al., 2013). Furthermore, PA bacterial decomposition of POM may release labile DOM into the surrounding waters which, because of chemotaxis, would be another possible reason for higher species richness of the FL fractions. In certain cases, chemolithotrophic species can be important source of FL bacteria in the deep ocean (Herndl and Reinthaler, 2013).

\section{The Effect of Depth and Other Environmental Factors}

Beta diversity analysis showed that bacterial communities in the NBT water column mainly clustered according to the pelagic 
zones. However, the PA and FL communities within each zone tend to grouped separately (Figure 3). ANOSIM analysis showed that there were significant differences in microbial communities between the pelagic zones and no significant differences between communities of the two trophic lifestyles (i.e., PA and FL) in the whole water column (Table 1). These results suggest that vertical stratification is a key factor in shaping bacterial community structure in the NBT water column.

It is also clear that depth and other environmental factors seem to have different impact on the PA and FL bacterial communities. As shown in CCA analysis, most of the variations in species composition of the FL bacterial communities can be explained by the first two CCA axes (66.1\%), but much less so for the PA bacterial communities (55.9\%) (Figure 4). This finding suggests that the FL bacterial communities are likely more responsive to the depth-related variations of environmental factors tested in this study. Consequently, the magnitude of changes in bacterial diversity with depth was much larger for the FL communities than that for the PA communities (Supplementary Figure S5). Further analysis showed that phosphate exhibited statistically significant correlation with the vertical variations of the PA bacterial communities, and pressure and PON concentration co-varied with the vertical pattern of the FL bacterial communities. The results suggest that the PA and FL bacterial communities may respond to, and be controlled by, different environmental factors. It is reasonably assumed that particles are enriched with organic matter and inorganic matters (e.g., phosphate), and therefore a close co-variation between bacterial communities and phosphate concentration is not unexpected. Previous studies have shown that surface attachment and the subsequent production of shielding biofilm matrix and stress response products may protect bacteria from environmental variability, such as temperature extremes (Wiebe et al., 1992; Dang and Lovell, 2016). Also, the content of organic matter on particles is much higher than that in the bulk seawater (Fang et al., 2015; Dang and Lovell, 2016). Thus, the PA communities may be less affected by variations in the amount of organic matter and physical variables in seawater, comparing to the FL bacterial communities. In contrast, the FL bacteria living in the bulk seawater exposes directly to the effect of physical factors such as pressure, and their survival mainly rely on consumption of DOM (Azam and Malfatti, 2007; Arnosti, 2011; Fang et al., 2015), it is therefore reasonable to observe significant correlations between POM (PON in this study) and physical factors (e.g., pressure) and the vertical variations of FL bacterial community. Pressure has long been recognized as an important factor affecting species composition of marine bacterial communities in laboratory incubation experiments (Grossart and Gust, 2009; Tamburini et al., 2013; Marietou and Bartlett, 2014). However, reports on relationships between pressure and variations of bacterial communities in natural oceanic habitats are scarce. Here, we provide direct evidence showing the significant effect of pressure in shaping bacterial community structure from the surface ocean to the abyssopelagic zone of the New Britain Trench (Figure 4), further supporting the potential significance of pressure-adapted piezophilic bacteria and their role in mediating biogeochemical cycles in the deep ocean (Fang et al., 2010, 2015).

\section{Distribution of Different Bacterial Lineages in PA and FL Fractions at Different Depths}

Significant differences in species composition between the PA and FL bacterial communities are frequently reported (Wilkins et al., 2013; Salazar et al., 2016; Milici et al., 2017). It seems reasonable to postulate that many taxa that adapted exclusively to either PA or FL lifestyle exist in the ocean, leading to the overall community level differences. However, our results revealed that, although there were on average 33 and $35 \%$ of the total OTUs exclusively presented in the PA and FL communities, respectively, these OTUs only accounted for minor proportions of the total sequences retrieved (Figure 5). The majority of the sequences (61.0-95.3\%) belonged to OTUs that were shared between the PA and FL communities (Figure 5). We further analyzed the major OTUs responsible for discriminating the PA and FL bacterial communities (the "indicative OTUs"). Our results suggest that the majority of the "indicative OTUs" are those that were shared between the PA and FL communities and that had much higher relative abundances in one type of the communities (Figure 6). In other words, the differences in community structure between the PA and FL bacterial communities tested in this study are mainly due to the uneven distribution of the shared OTUs in the PA and FL fractions. High percentage of sequences belonging to shared OTUs in PA and FL bacteria have also been observed in several previous studies in surface water (Crespo et al., 2013; Yung et al., 2016) and mesopelagic water (Hollibaugh et al., 2000; Moeseneder et al., 2001; Ghiglione et al., 2007). Our study is the first to extend such observations into bathy- and abyssopelagic waters, and the findings suggest that shared OTUs between PA and FL bacterial communities may be common at different depths and in different locations of the ocean. It is not yet known the exact reasons for the shared OTUs in the PA and FL bacterial communities. It is possible that certain taxa have attained the mechanisms to switch between the two lifestyles for the purpose of accessing carbon and nutrients (Fang et al., 2015; Dang and Lovell, 2016). Alternatively, these OTUs contain sub-OTUs that show sub-OTU level or strain level habitat specialization (Hunt et al., 2008; Yung et al., 2015). Further studies exploring the true reasons behind the shared OTUs in both lifestyles are important for understanding the mechanisms of remineralization of POM and DOM in the ocean.

Although the majority of the sequences belonging to OTUs present in both PA and FL communities, most of these shared OTUs showed obvious enrichment on one lifestyle (Figure 6). The enrichment of different bacterial taxa on PA or FL lifestyle was more obvious at the class level: the PA community contained higher proportions of species belonging to Cyanobacteria, Bacilli (Firmicutes), Flavobacteria (Bacteroidetes) and Actinobacteria throughout the water column (Figure 2). Due to the phototrophic nature of Cyanobacteria, these bacteria may not be playing an active role in the deep water, but the presence of Cyanobacteria in the PA bacterial communities throughout the 
water column may serve as an indication of bacteria attachment to and vertical transport of particles and the attached bacteria. It is also possible that this represents an artifact of filtration as the size of certain Cyanobacteria taxa is much greater than the pore size of the filter we utilized $(3 \mu \mathrm{m})$. Alternatively, the detected Cyanobacteria might be dead cells and serve as substrates for PA bacteria, which are transported to the deep water. Association of taxa from Firmicutes and Bacteroidetes with PA lifestyle has been reported in the bathypelagic oceans globally (Salazar et al., 2015), which could be related to their capability of degrading complex organic matters such as polymers (Cottrell and Kirchman, 2000). Actinobacteria has also been demonstrated to produce various extracellular hydrolytic enzymes and degrade a wide range of organics, including refractory organics such as polycyclic aromatic hydrocarbons and polysaccharides (Chen et al., 2016). Different from their PA counterparts, the FL bacterial communities contained much higher proportions of SAR406 and SAR202, especially in the deep water (Figure 2). Enrichment of these two groups in the FL fraction of the deep ocean has also been reported in previous studies (Salazar et al., 2015; Milici et al., 2017). Bacteria from those two groups generally have streamlined genomes and adapted to the oligotrophic conditions in the deep (DeLong et al., 2006; Eloe et al., 2011a; Giovannoni et al., 2014). In addition, the most dominant classes, i.e., Gamma-, Alpha-, and Deltaproteobacteria showed mixed distributions between the PA and FL communities, as reported in the literature (Eloe et al., 2011b; Li et al., 2015; Salazar et al., 2015; Milici et al., 2017). Our results support the hypothesis that high bacterial taxonomic ranks (Class/Phylum) have conserved lifestyles, either in association with particles or as FL (Eloe et al., 2011b; Salazar et al., 2015).

\section{CONCLUSION}

We investigated for the first time the vertical variations of abundance and diversity of PA and FL bacterial communities from surface ocean to abyssopelagic waters in the New Britain Trench. Our results revealed distinct patterns of PA and FL bacterial communities on their vertical variations of relative abundance, species richness, species compositions as well as their relationships with environmental factors. The PA bacteria showed increasing relative abundance with depth, suggesting the increased ecological significance of the PA lifestyle in the deep ocean. Vertical variations of the species compositions of PA and FL bacterial communities were found to be significantly associated with different sets of environmental factors, and FL bacteria were more responsive to changes of environmental variables tested. The differences on their relationships with environmental factors might be due to the different micro-niches of the PA and FL bacterial communities. Analysis of species distribution between $\mathrm{PA}$ and FL communities revealed that

\section{REFERENCES}

Agogué, H., Lamy, D., Neal, P. R., Sogin, M. L., and Herndl, G. J. (2011). Water mass-specificity of bacterial communities in the north Atlantic revealed by majority of sequences are belonging to OTUs shared between two communities, and the enrichment of these shared OTUs in either PA or FL lifestyle was the major reason for differences between the two bacterial communities. These findings provide new insights to the bacterial adaptation of different lifestyles. However, the reasons of shared taxa in both lifestyles and the implications to the marine carbon cycles need to be further addressed in the following studies.

\section{DATA ACCESSIBILITY}

All raw sequences used in this study are publicly available at the NCBI Sequence Read Archive (SRA, http://www.ncbi.nlm.nih. gov/Traces/sra) under accession ID SRP125714.

\section{AUTHOR CONTRIBUTIONS}

RL, LW, and JF designed the expedition and sampling scheme, analyzed the data, and wrote the article. QL and RL prepared the samples on board. LW, QL, ZW, and ZL conducted the experimental procedures including cell counting, DNA extraction, PCR amplification, qPCR analysis, and bioinformatics analysis. ML measured all chemical parameters. RL, LW, QL, ZW, $\mathrm{ZL}$, JF, and LZ made comments and suggestions to improve the manuscript.

\section{FUNDING}

This work was supported by the Program for Professor of Special Appointment (Eastern Scholar) at Shanghai Institutions of Higher Learning (Grant No. QD2016053) and the initial funding of Shanghai Ocean University (Grant Nos. A2-0203-17100309, A2-0203-00-100309, B1-5008-13-0111-2, and A1-203517-0002C2-4). JF acknowledges the support of the National Natural Science Foundation of China (Grant Nos. 41773069, 91328208, and 41373071).

\section{ACKNOWLEDGMENTS}

We thank crews of R/V Zhangjian, members of the Rainbowfish company, and the scientific team of the NBT-1 cruise for their assistance in sampling.

\section{SUPPLEMENTARY MATERIAL}

The Supplementary Material for this article can be found online at: https://www.frontiersin.org/articles/10.3389/fmicb. 2018.00625/full\#supplementary-material

massively parallel sequencing. Mol. Ecol. 20, 258-274. doi: 10.1111/j.1365-294X. 2010.04932.x

Arístegui, J., Gasol, J. M., Duarte, C. M., and Herndld, G. J. (2009). Microbial oceanography of the dark ocean's pelagic 
realm. Limnol. Oceanogr. 54, 1501-1529. doi: 10.4319/lo.2009.54.5. 1501

Arnosti, C. (2011). Microbial extracellular enzymes and the marine carbon cycle. Annu. Rev. Mar. Sci. 3, 401-425. doi: 10.1146/annurev-marine-120709-142731

Azam, F., and Malfatti, F. (2007). Microbial structuring of marine ecosystems. Nat. Rev. Microbiol. 5, 782-791. doi: 10.1038/nrmicro1747

Bižic-Ionescu, M., Zeder, M., Ionescu, D., Orlic, S., Fuchs, B. M., Grossart, H. P., et al. (2014). Comparison of bacterial communities on limnic versus coastal marine particles reveals profound differences in colonization. Environ. Microbiol. 17, 3500-3514. doi: 10.1111/1462-2920.12466

Bolger, A. M., Lohse, M., and Usadel, B. (2014). Trimmomatic: a flexible trimmer for Illumina sequence data. Bioinformatics 30, 2114-2120. doi: 10.1093/bioinformatics/btu170

Brown, M. V., Philip, G. K., Bunge, J. A., Smith, M. C., Bissett, A., Lauro, F. M., et al. (2009). Microbial community structure in the north pacific ocean. ISME J. 3, 1374-1386. doi: 10.1038/ismej.2009.86

Cai, L., Ye, L., Tong, A. H. Y., Lok, S., and Zhang, T. (2013). Biased diversity metrics revealed by bacterial $16 \mathrm{~S}$ pyrotags derived from different primer sets. PLoS One 8:e53649. doi: 10.1371/journal.pone.0053649

Chen, P., Zhang, L., Guo, X., Dai, X., Liu, L., Xi, L., et al. (2016). Diversity, biogeography, and biodegradation potential of actinobacteria in the deepsea sediments along the southwest Indian ridge. Front. Microbiol. 7:1340. doi: $10.3389 /$ fmicb.2016.01340

Chen, W., Cai, P., Dai, M., and Wei, J. (2008). ${ }^{234} \mathrm{Th} /{ }^{238} \mathrm{U}$ disequilibrium and particulate organic carbon export in the northern South China Sea. J. Oceanogr. 64, 417-428. doi: 10.1007/s10872-008-0035-z

Clarke, K. R., and Warwick, R. M. (2001). Change in Marine Communities: An Approach to Statistical Analysis and Interpretation, 2nd Edn. Plymouth: PRIMER-E.

Cottrell, M. T., and Kirchman, D. L. (2000). Natural assemblages of marine proteobacteria and members of the Cytophaga-Flavobacter cluster consuming low- and high-molecular-weight dissolved organic matter. Appl. Environ. Microbiol. 66, 1692-1697. doi: 10.1128/AEM.66.4.1692-1697.2000

Crespo, B. G., Pommier, T., Fernández-Gómez, B., and Pedrós-Alió, C. (2013). Taxonomic composition of the particle-attached and free-living bacterial assemblages in the Northwest Mediterranean Sea analyzed by pyrosequencing of the 16S rRNA. Microbiologyopen 2, 541-552. doi: 10.1002/mbo3.92

Dang, H., and Lovell, C. R. (2016). Microbial surface colonization and biofilm development in marine environments. Microbiol. Mol. Biol. Rev. 80, 91-138. doi: 10.1128/MMBR.00037-15

DeLong, E. F., Preston, C. M., Mincer, T., Rich, V., Hallam, S. J., Frigaard, N. U., et al. (2006). Community genomics among stratified microbial assemblages in the ocean's, interior. Science 311, 496-503. doi: 10.1126/science.1120250

Ducklow, H. W., Steinberg, D. K., and Buesseler, K. O. (2001). Upper ocean carbon export and the biological pump. Oceanography 14, 50-58. doi: 10.5670/oceanog. 2001.06

Eloe, E. A., Fadrosh, D. W., Novotny, M., Allen, L., Kim, M., Lombardo, M. J., et al. (2011a). Going deeper: metagenome of a hadopelagic microbial community. PLoS One 6:e20388. doi: 10.1371/journal.pone.0020388

Eloe, E. A., Shulse, C. N., Fadrosh, D. W., Williamson, S. J., Allen, E. E., and Bartlett, D. H. (2011b). Compositional differences in particle-associated and free-living microbial assemblages from an extreme deep-ocean environment. Environ. Microbiol. Rep. 3, 449-458. doi: 10.1111/j.1758-2229.2010.00223.x

Fang, J., Zhang, L., and Bazylinski, D. A. (2010). The deep-sea piezosphere and piezophiles: geomicrobiology and biogeochemistry. Trends Microbiol. 18, 413-422. doi: 10.1016/j.tim.2010.06.006

Fang, J. S., Li, Z., Tao, L. J., Kato, C., Tamburini, C., Zhang, Y. Z., et al. (2015). The POM-DOM piezophilic microorganism continuum (PDPMC) - the role of piezophilic microorganisms in the global ocean carbon cycle. Sci. China Earth Sci. 58, 106-115. doi: 10.1007/s11430-014-4985-2

Ghiglione, J. F., Galand, P. E., Pommier, T., Pedros-Alio, C., Maas, E. W., Bakker, K., et al. (2012). Pole-to-pole biogeography of surface and deep marine bacterial communities. Proc. Natl. Acad. Sci. U.S.A. 109, 17633-17638. doi: 10.1073/pnas.1208160109

Ghiglione, J. F., Mevel, G., Pujo-Pay, M., Mousseau, L., Lebaron, P., and Goutx, M. (2007). Diel and seasonal variations in abundance, activity, and community structure of particle-attached and free-living bacteria in NW Mediterranean Sea. Microb. Ecol. 54, 217-231. doi: 10.1007/s00248-006-9189-7
Giovannoni, S. J., Cameron Thrash, J., and Temperton, B. (2014). Implications of streamlining theory for microbial ecology. ISME J. 8, 1553-1565. doi: 10.1038/ ismej.2014.60

Glud, R. N., Wenzhofer, F., Middelboe, M., Oguri, K., Turnewitsch, R., Canfield, D. E., et al. (2013). High rates of microbial carbon turnover in sediments in the deepest oceanic trench on Earth. Nat. Geosci. 6, 284-288. doi: 10.1038/ NGEO1773

Grossart, H. P., and Gust, G. (2009). Hydrostatic pressure affects physiology and community structure of marine bacteria during settling to $4000 \mathrm{~m}$ : an experimental approach. Mar. Ecol. Prog. 390, 97-104. doi: 10.3354/meps08201

Herndl, G. J., and Reinthaler, T. (2013). Microbial control of the dark end of the biological pump. Nat. Geosci. 6, 718-724. doi: 10.1038/ngeo1921

Hollibaugh, J. T., Wong, P. S., and Murrell, M. C. (2000). Similarity of particleassociated and free-living bacterial communities in northern San Francisco Bay, California. Aquat. Microb. Ecol. 21, 103-114. doi: 10.3354/ame021103

Hunt, D. E., David, L. A., Gevers, D., Preheim, S. P., Alm, E. J., and Polz M. F. (2008). Resource partitioning and sympatric differentiation among closely related bacterioplankton. Science 320, 1081-1085. doi: 10.1126/science.1157890

Ichino, M. C., Clark, M. R., Drazen, J. C., Jamieson, A., Jones, D. O. B., Martin, A. P., et al. (2015). The distribution of benthic biomass in hadal trenches: a modelling approach to investigate the effect of vertical and lateral organic matter transport to the seafloor. Deep Sea Res. Part I Oceanogr. Res. Pap. 100, 21-33. doi: 10.1016/j.dsr.2015.01.010

Jamieson, A. J., Fujii, T., Mayor, D. J., Solan, M., and Priede, I. G. (2010). Hadal trenches: the ecology of the deepest places on Earth. Trends Ecol. Evol. 25, 190-197. doi: 10.1016/j.tree.2009.09.009

Jiao, N., Herndl, G. J., Hansell, D. A., Benner, R., Kattner, G., Wilhelm, S. W., et al. (2010). Microbial production of recalcitrant dissolved organic matter: long-term carbon storage in the global ocean. Nat. Rev. Microbiol. 8, 593-599. doi: 10.1038/nrmicro2386

Jiao, N., Robinson, C., Azam, F., Thomas, H., Baltar, F., Dang, H., et al. (2014). Mechanisms of microbial carbon sequestration in the ocean - future research directions. Biogeosciences 11, 5285-5306. doi: 10.5194/bg-11-5285-2014

Kiørboe, T., Tang, K., Grossart, H. P., and Ploug, H. (2003). Dynamics of microbial communities on marine snow aggregates: colonization, growth, detachment, and grazing mortality of attached bacteria. Appl. Environ. Microbiol. 69, 30363047. doi: 10.1128/AEM.69.6.3036-3047.2003

Lauro, F. M., McDougald, D., Thomas, T., Williams, T. J., Egan, S., Rice, S., et al. (2009). The genomic basis of trophic strategy in marine bacteria. Proc. Natl. Acad. Sci. U.S.A. 106, 15527-15533. doi: 10.1073/pnas.0903507106

Li, J., Wei, B., Wang, J., Liu, Y., Dasgupta, S., Zhang, L., et al. (2015). Variation in abundance and community structure of particle-attached and free-living bacteria in the South China Sea. Deep Sea Res. Part II Top. Stud. Oceanogr. 122, 64-73. doi: 10.1016/j.dsr2.2015.07.006

Liu, R., Wang, L., Wei, Y., and Fang, J. (2017). The hadal biosphere: recent insights and new directions. Deep Sea Res. Part II Top. Stud. Oceanogr. doi: 10.1016/j. dsr2.2017.04.015 [Epub ahead of print].

Liu, R. L., Zhang, Y., and Jiao, N. Z. (2010). Diel variations in frequency of dividing cells and abundance of aerobic anoxygenic phototrophic bacteria in a coral reef system of the South China Sea. Aquat. Microb. Ecol. 58, 303-310. doi: 10.3354/ame01371

Magoc, T., and Salzberg, S. L. (2011). FLASH: fast length adjustment of short reads to improve genome assemblies. Bioinformatics 27, 2957-2963. doi: 10.1093/ bioinformatics/btr507

Marietou, A., and Bartlett, D. H. (2014). Effects of high hydrostatic pressure on coastal bacterial community abundance and diversity. Appl. Environ. Microbiol. 80, 5992-6003. doi: 10.1128/AEM.02109-14

Milici, M., Vital, M., Tomasch, J., Badewien, T. H., Giebel, H. A., Plumeier, I., et al. (2017). Diversity and community composition of particle-associated and freeliving bacteria in mesopelagic and bathypelagic Southern Ocean water masses: evidence of dispersal limitation in the Bransfield Strait. Limnol. Oceanogr. 62, 1080-1095. doi: 10.1002/lno.10487

Moeseneder, M. M., Winter, C., and Herndl, G. J. (2001). Horizontal and vertical complexity of attached and free-living bacteria of the eastern Mediterranean Sea, determined by $16 \mathrm{~S}$ rDNA and $16 \mathrm{~S}$ rRNA fingerprints. Limnol. Oceanogr. 46, 95-107. doi: 10.4319/lo.2001.46.1.0095

Mohit, V., Archambault, P., Toupoint, N., and Lovejoy, C. (2014). Phylogenetic differences in attached and free-living bacterial communities in a temperate 
coastal lagoon during summer, revealed via high-throughput 16S rRNA gene sequencing. Appl. Environ. Microbiol. 80, 2071-2083. doi: 10.1128/AEM.02 916-13

Nunoura, T., Hirai, M., Yoshida-Takashima, Y., Nishizawa, M., Kawagucci, S., Yokokawa, T., et al. (2016). Distribution and niche separation of planktonic microbial communities in the water columns from the surface to the hadal waters of the Japan trench under the eutrophic ocean. Front. Microbiol. 7:1261. doi: 10.3389/fmicb.2016.01261

Nunoura, T., Takaki, Y., Hirai, M., Shimamur, S., Makabe, A., Koide, O., et al. (2015). Hadal biosphere: insight into the microbial ecosystem in the deepest ocean on Earth. Proc. Natl. Acad. Sci. U.S.A. 112, E1230-E1236. doi: 10.1073/ pnas. 1421816112

Oliveros, J. C. (2007-2015). VENNY. An Interactive Tool for Comparing Lists with Venn Diagrams. BioinfoGP of CNB-CSIC. Available at: http://bioinfogp.cnb.csic. es/tools/venny/index.html

Rieck, A., Herlemann, D. P. R., Jürgens, K., and Grossart, H. P. (2015). Particleassociated differ from free-living bacteria in surface waters of the Baltic sea. Front. Microbiol. 6:1297. doi: 10.3389/fmicb.2015.01297

Salazar, G., Cornejo-Castillo, F. M., Benitez-Barrios, V., Fraile-Nuez, E., AlvarezSalgado, X. A., Duarte, C. M., et al. (2016). Global diversity and biogeography of deep-sea pelagic prokaryotes. ISME J. 10, 596-608. doi: 10.1038/ismej. 2015.137

Salazar, G., Cornejo-Castillo, F. M., Borrull, E., Díez-Vives, C., Lara, E., Vaqué, D., et al. (2015). Particle-association lifestyle is a phylogenetically conserved trait in bathypelagic prokaryotes. Mol. Ecol. 24, 5692-5706. doi: 10.1111/mec.13419

Starke, I. C., Vahjen, W., Pieper, R., and Zentek, J. (2014). The influence of DNA extraction procedure and primer set on the bacterial community analysis by pyrosequencing of barcoded $16 \mathrm{~S}$ rRNA gene amplicons. Mol. Biol. Int. 2014:548683. doi: 10.1155/2014/548683

Tamburini, C., Boutrif, M., Garel, M., Colwell, R. R., and Deming, J. W. (2013). Prokaryotic responses to hydrostatic pressure in the ocean-a review. Environ. Microbiol. 15, 1262-1274. doi: 10.1111/1462-2920.12084

Tarn, J., Peoples, L. M., Hardy, K., Cameron, J., and Bartlett, D. H. (2016). Identification of free-living and particle-associated microbial communities present in hadal regions of the mariana trench. Front. Microbiol. 7:665. doi: $10.3389 /$ fmicb.2016.00665

Ter Braak, C. J. F. (1986). Canonical correspondence analysis: a new eigenvector technique for multivariate direct gradient analysis. Ecology 67, 1167-1179. doi: $10.2307 / 1938672$

Thijs, S., De Beeck, M. O., Beckers, B., Truyens, S., Stevens, V., Van Hamme, J. D., et al. (2017). Comparative evaluation of four bacteria-specific primer pairs for 16S rRNA gene surveys. Front. Microbiol. 8:494. doi: 10.3389/fmicb.2017. 00494

Thrash, J. C., Temperton, B., Swan, B. K., Landry, Z. C., Woyke, T., DeLong, E. F., et al. (2014). Single-cell enabled comparative genomics of a deep ocean SAR11 bathytype. ISME J. 8, 1440-1451. doi: 10.1038/ismej. 2013.243

Vahjen, W., Pieper, R., and Zentek, J. (2010). Bar-coded pyrosequencing of 16S rRNA gene amplicons reveals changes in ileal porcine bacterial communities due to high dietary zinc intake. Appl. Environ. Microbiol. 76, 6689-6691. doi: 10.1128/AEM.03075-09

Walsh, E. A., Kirkpatrick, J. B., Rutherford, S. D., Smith, D. C., Sogin, M., and D'Hondt, S. (2016). Bacterial diversity and community composition from seasurface to subseafloor. ISME J. 10, 979-989. doi: 10.1038/ismej.2015.175

Wang, S. L., Hong, Y. G., Wu, J. P., Xu, X. R., Bin, L. Y., Pan, Y. P., et al. (2015). Comparative analysis of two $16 \mathrm{~S}$ rRNA gene-based PCR primer sets provides insight into the diversity distribution patterns of anammox bacteria in different environments. Appl. Microbiol. Biotechnol. 99, 8163-8176. doi: 10.1007/s00253015-6814-8

Wiebe, W. J., Sheldon, W. M., and Pomeroy, L. R. (1992). Bacterial growth in the cold: evidence for an enhanced substrate requirement. Appl. Environ. Microbiol. 58, 359-364.

Wilkins, D., van Sebille, E., Rintoul, S. R., Lauro, F. M., and Cavicchioli, R. (2013). Advection shapes Southern Ocean microbial assemblages independent of distance and environment effects. Nat. Commun. 4:2457. doi: 10.1038/ ncomms 3457

Yung, C. M., Vereen, M. K., Herbert, A., Davis, K. M., Yang, J., Kantorowska, A., et al. (2015). Thermally adaptive tradeoffs in closely-related marine bacterial strains. Environ. Microbiol. 17, 2421-2429. doi: 10.1111/1462-2920. 12714

Yung, C. M., Ward, C. S., Davis, K. M., Johnson, Z. I., and Hunt, D. E. (2016). Insensitivity of diverse and temporally variable particle-associated microbial communities to bulk seawater environmental parameters. Appl. Environ. Microbiol. 82, 3431-3437. doi: 10.1128/AEM.00395-16

Zhang, Y., Xiao, W., and Jiao, N. Z. (2016). Linking biochemical properties of particles to particle-attached and free-living bacterial community structure along the particle density gradient from freshwater to open ocean. J. Geophys. Res. Biogeosci. 121, 2261-2274. doi: 10.1002/2016JG003390

Conflict of Interest Statement: The authors declare that the research was conducted in the absence of any commercial or financial relationships that could be construed as a potential conflict of interest.

Copyright (c) 2018 Liu, Wang, Liu, Wang, Li, Fang, Zhang and Luo. This is an open-access article distributed under the terms of the Creative Commons Attribution License (CC BY). The use, distribution or reproduction in other forums is permitted, provided the original author(s) and the copyright owner are credited and that the original publication in this journal is cited, in accordance with accepted academic practice. No use, distribution or reproduction is permitted which does not comply with these terms. 